\title{
Brief on Retinal Detachment and Central Serous Retinopathy
}

\section{Dr Partha Haradhan Chowdhury ${ }^{1 *}$ and Brinda Haren Shah ${ }^{2}$}

${ }^{1}$ Ph.D. in Optometry (Gujarat State Government University) and Professor and

Principal, Shree Satchandi Jankalyan Samiti Eye Institute - Pauri, Uttarakhand, India

${ }^{2}$ M. OPTOM, Practitioner, Ahmedabad, Gujarat, India

*Corresponding Author: Dr Partha Haradhan Chowdhury, Ph.D. in Optometry (Gujarat State Government University) and Professor and Principal, Shree Satchandi Jankalyan Samiti Eye Institute - Pauri, Uttarakhand, India.
Received: March 23, 2021

Published: April 16, 2021

(C) All rights are reserved by Dr Partha

Haradhan Chowdhury and Brinda Haren

Shah.

\begin{abstract}
This paper describes about basics of retinal detachment and central serous retinopathy.

Keywords: Retinal Detachment; Central Serous Retinopathy; Retina
\end{abstract}

\section{Introduction}

Retinal detachment is a condition where RPE layer is separated from the rest layers of the retina. Rest layers of retina are called sensory layers. But, any localized break of the retina or splitting of the retina is also considered as retinal detachment.

\section{Retinal Detachment}

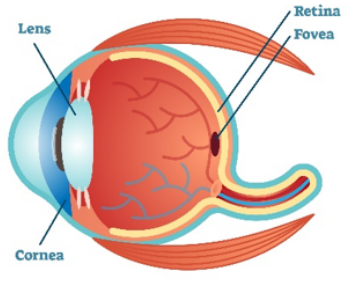

Healthy Eye

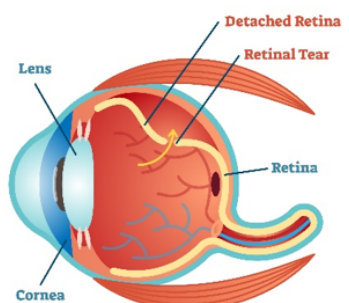

Retinal Detachment
Classification:

- Rhegmatogenous retinal detachment

- Non rhegmatogenous retinal detachment

- Rhegmatogenous retinal detachment.

The meaning of Rhegma is break. So, in case of rhegmatogenous retinal detachment retinal break is present and sub retinal fluid enters here from the vitreous.

Non rhegmatogenous retinal detachment

Here, retinal break is not found but it mainly occurs due to

- Tractional retinal detachment

- Exudative retinal detachment.

\section{Tractional retinal detachment}

It mainly occurs due to retinal pigmented epithelium layer is pulled away from the sensory layers due to proliferative diabetic retinopathy and trauma.

Figure 1 


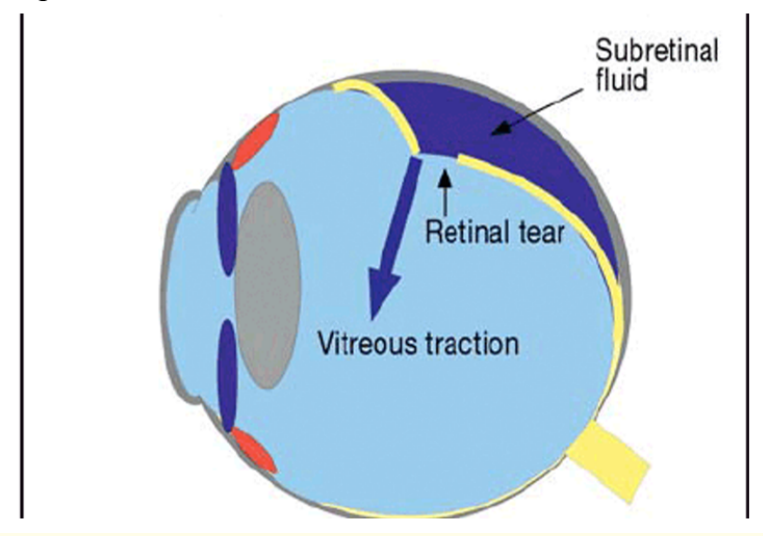

Figure 2

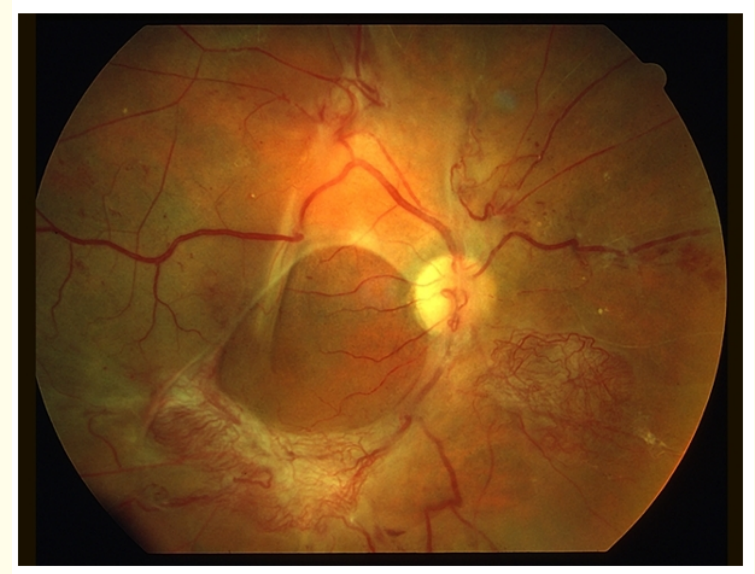

Figure 3

\section{Exudative retinal detachment}

It mainly occurs due to fluid is derived from the choroid through the damage of RP layer. The reason is choroidal tumor or inflammation.

\section{Clinical features:}

- Deterioration of visual acuity

- Presence of RAPD

- Presence of photopsia

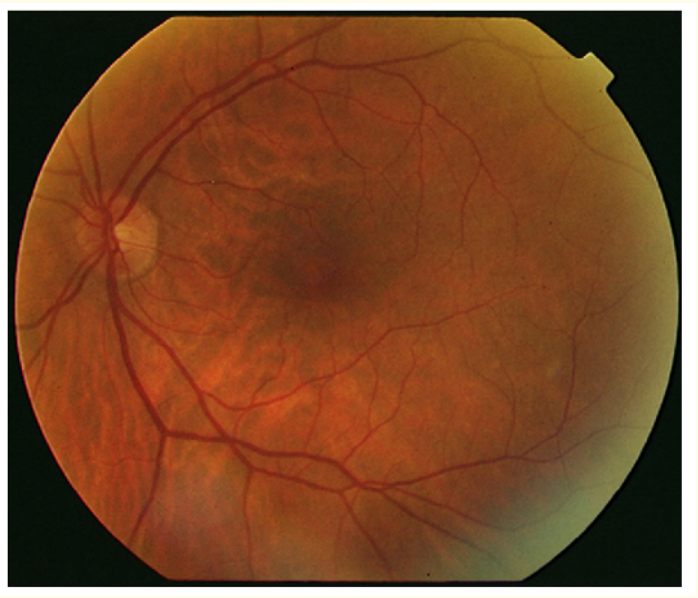

Figure 4

- Presence of metamorphopsia

- Retinal thinning.

\section{Treatment:}

- To treat retinal detachment,

- For rhegmatogenous retinal detachment-

- To find the break

- $\quad$ To seal the break

- For the retinal detachment surgery, most of the time, always advise for

- Vitrectomy

- Scleral buckling

- Pneumatic retinopathy.

\section{Central serous retinopathy}

In case of CSR, sudden macular edema is present. Actually, it is a type of localized retinal detachment. Typically, young adult males are affected more due to unknown cause. Usually, central serous retinopathy is associated with hypermetropic refractive error and most of the time prognosis is good. Here visual acuity is deteriorated up to $6 / 9$ to $6 / 18$. Low plus spherical power is prescribed for the correction. In case of CSR, sudden blurring of vision occurs.

Usually, no treatment is required in this case. 


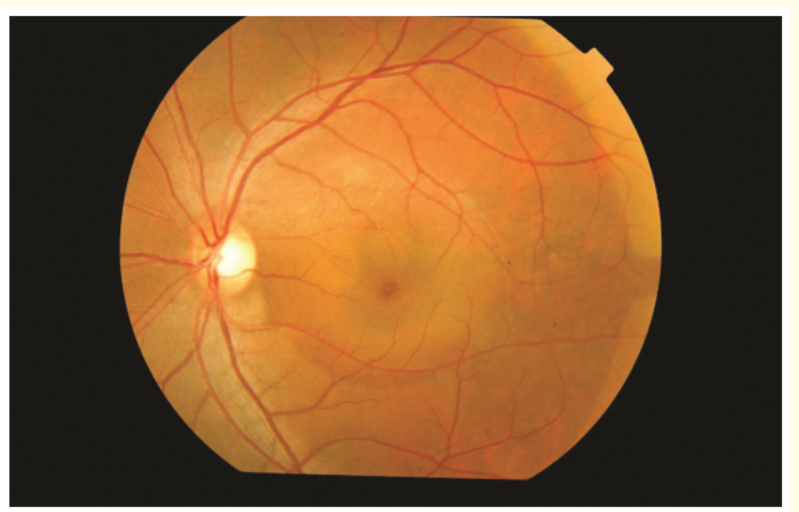

Figure 5

Sometimes due to leakage argon laser or double frequency YAG laser is advised [1-3].

\section{Bibliography}

1. Brad Bowling. "Kanski's Clinical Ophthalmology E-Book: A Systematic Approach". $8^{\text {th }}$ Edition (2016).

2. Sihota Radhika Tandon. "Parson's Diseases of the Eye". $22^{\text {nd }}$ Edition (2018).

3. Samar K Basak. "Clinical Ophthalmology” (2009).

\section{Assets from publication with us}

- Prompt Acknowledgement after receiving the article

- Thorough Double blinded peer review

- Rapid Publication

- Issue of Publication Certificate

- High visibility of your Published work

Website: www.actascientific.com/

Submit Article: www.actascientific.com/submission.php

Email us: editor@actascientific.com

Contact us: +919182824667 